\title{
جوهر الحضارة الإسلامية وتجلياتها \\ قراءة في كتاب "أطلس الحضارة الإسلامية" \\ تأليف: إسماعيل راجي الفاروقي ولوس لمياء الفاروقي
}

\section{فتحي حسن ملكاوي}

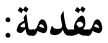

لا يـراودُ القـارئُ شـكُّ في أنَّ ديسنَ الإسـاملام، هـو جـوهرُ الحضــارة الإسـلامية، وأنَّ التوحيدَ هو جوهرُ هذا الدين؛ إذلم تصطبغ أية حضارة في القـديم والحمديث بطابع ديني

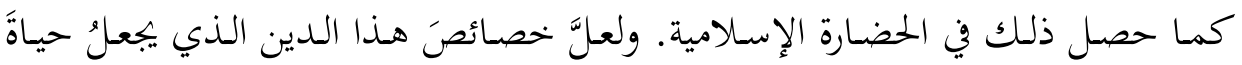

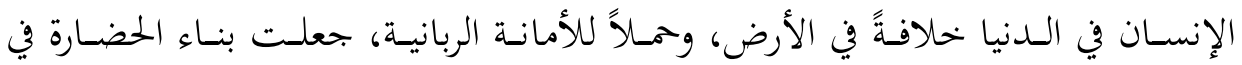

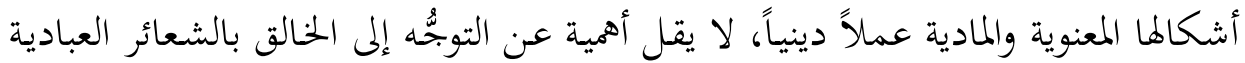

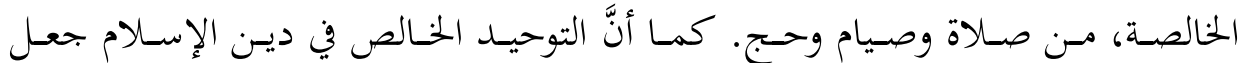

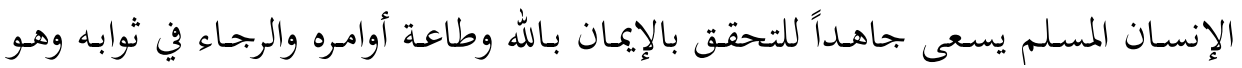
يمارس الإنتاج الزراعي، والتطوير الصناعي، والإبداع الفني، والتشييد العمراني، والتخطيط

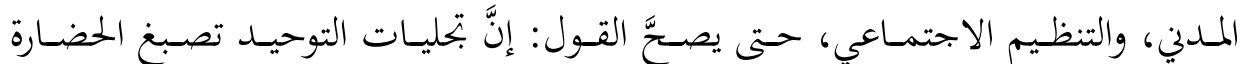
الإسلامية في سائر منجزاتما.

كيف يمكن أن يتحقق لنـا ذلك القـر مـن اليقـين في أن إحسـان العمل في شؤون الدنيا فيما تتقوَّم به الحياة وتترقّى أسباهُا، وتزدهر به الحضارة في بحالاتها المادية والمعنوية،

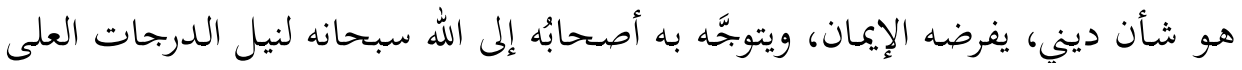
من ثواب الآخرة ونعيمها؟

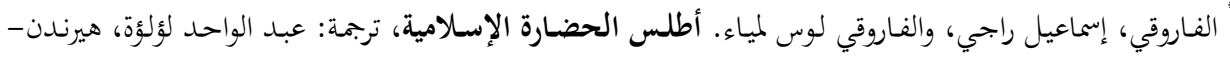

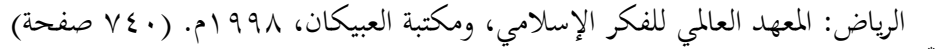

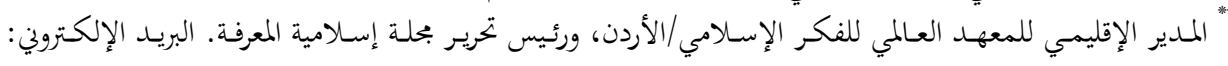
fathihmalkawi@gmail.com

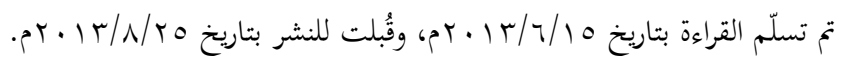




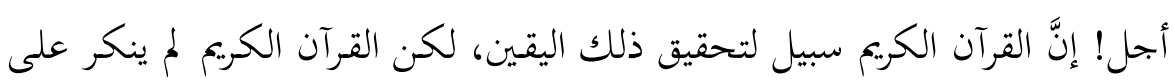

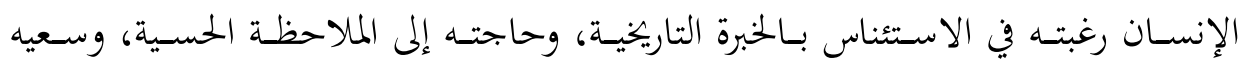
للاستدلال بالمشاهدات المادية، لتعزيز إيمانه بمـا يهدي إليه القرآن الكريم. ولعل القراءة المتأنية للكتاب، الذي نحن بصدد الحديث عنه، تكشف عن الإبداع الذي حققه المؤلفان في تحليل النصوص التاريخية والشواهد المادية للوصول إلى أنَّ التوحيد هو جوهر الإبندئ الحضارة الإسـلامية. وبهـذه القـراءة المتأنيـة يتحقـق ذلك اليقـين لغـير المسـلم بالاسـتناد إلى فاعليـة المنهج الذي يستخدمه المؤلفان، وقوة الحجـج التي يقدمافا، كما يتحقق ذلك للمسلم

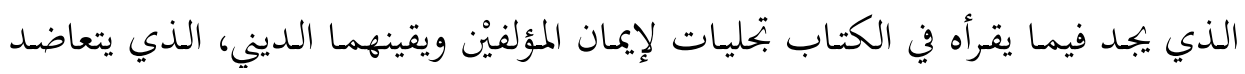
من خبرتما وكفاءهما العلمية.

الكتـاب الذي نحن بصده "أطلس الحضـارة الإسلامية" هـو الترجمة العربية للنسـخة الأصلية مـن الكتاب بعنوان: The Atlas of Islamic Civilization الصـادر

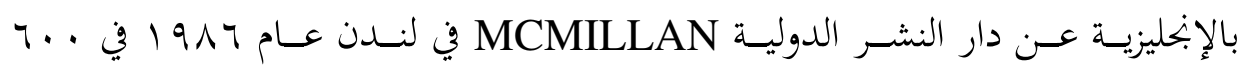
صفحة من القطع الكبير، بعد استشهاد المؤلفين في منزلمما بفترة قصيرة. ترجم الكتاب إلى ست لغات: الماليزية، والإندونيسية، والتركية، والإسبانية، والبرتغالية، والفارسية، قبل أن يُترجم إلى العربية.

مؤلفـا الكتـاب إسماعيل راجي الفـاروقي، وزوجته لوس لمياء الفـاروقي. ولد إسماعيل إسماعيل الفاروقي في فلسطين، وتخصص في الدراسات الفلسفية، ودرس العلوم الإسلامية

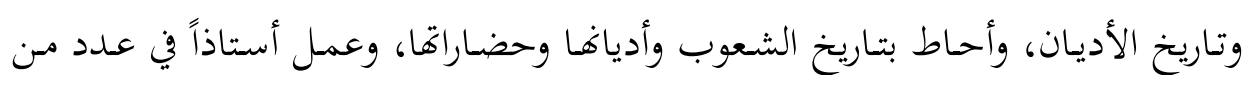
الجحامعات الكبرى في الولايات المتحـدة وكندا، وبتحول في بلدان العالم الإسلامي، وعمل أستاذا زائراً في كثير من جامعاقا، ونشر حوالي خمسة وعشرين كتاباً وأكثر من مائة بحث، إنها وشارك في تأليف "الأطلس التاريخي لأديان العالمُ" وموسوعة "الديانات الأسيوية الكبرى"

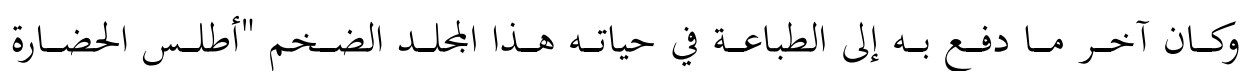

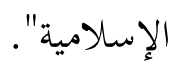


أما المؤلفة المشاركة في تأليف هذا الأطلس، فهي زوجة الدكتور إسماعيل الفاروقي، الــكتورة "لـوس لميـاء الفـاروقي" المتخصصــة في الدراسـات الإسـالمية والخبـيرة بـالفنون الإسلامية والموسيقى. وقد مارست التدريس والبحث والتأليف في مصطلحات الموسيقى العربيـة والفنـون الإسـلامية، وتـاريخ الموسيقى. وقــ جـرى اغتيـال المؤلفـان في منـزلمما في

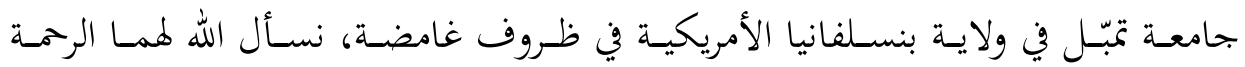

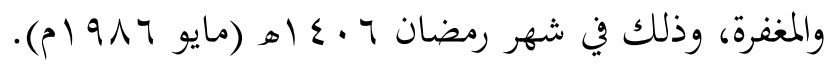

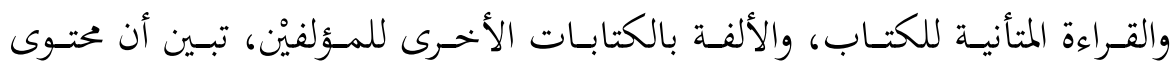
الكتاب يمثل خلاصـة الخببرة العلمية والبحثية للمولفين، فقد ظهرت معظم الموضوعات الواردة في الكتاب في البحوث المنشورة سابقاً لمما بصورة أكثر عمقاً وتفصيلاً. ولكنها تَرِدِ هنـا ضـمن بنيـة متكاملـة تكـاد تحسيط بموضـوعات الحضــارة الإسـامية، وأعلامهـا،

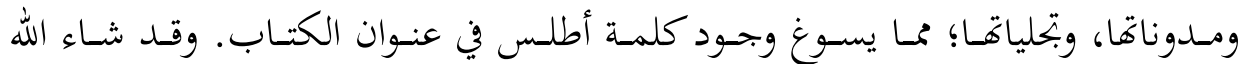
سبحانه أن يكون هذا الكتاب هو آخر ما يدفعان بـاء إلى الطباعة، قبل أن يلتحقا معاً

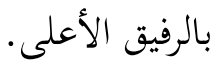

والجـدير بالـذكر أن المـترجم (وهـو يفضـل مصـطلح الناقـل بـديلاً عـن المـترجم) هـو

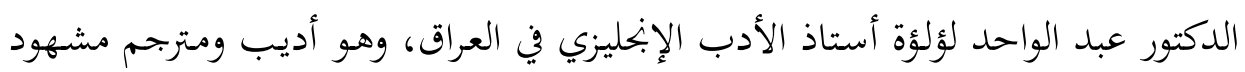
له بالكفاءة، وقد نوَّه في مقدمة الناقل بالمساعدة التي قدمتها زوجته مريم في ضبط العبارة

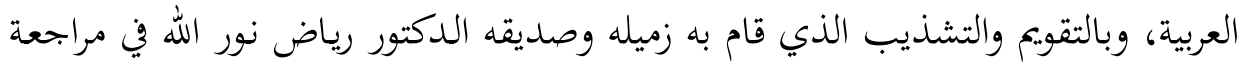
الترجمة.

وقد تعاون المعهد العالمي للفكر الإسلامي ومكتبة العبيكان في الرياض على القيام بكمة الترجمة والنشر.

البنية الكُلية للكتاب

تقع الترجمة العربية للكتاب في سبعمائة وأربعين صفحة من القطع الكبير. وقسمت ألمات مادة الكتاب إلى أربعة أقسام غير المقدمات والملاحق. تضمّ الأقسام الثلاثة الأولى ثمانية 


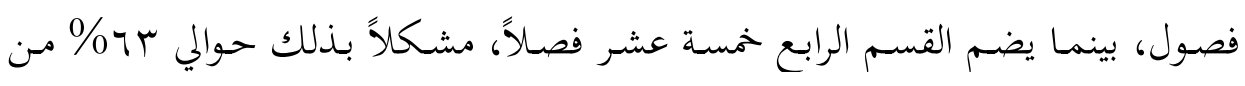

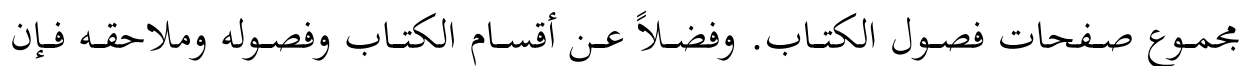

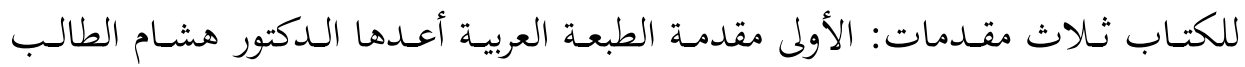

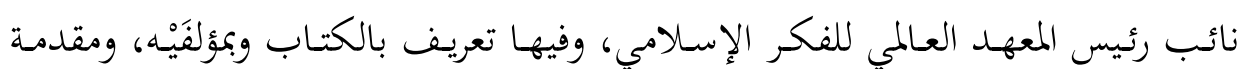
للمترجم أوضح فيها بعض عناصر منهجيته في الترجمة، ومقدمة المؤلفيْن. وكما هو متوقع مـن مقدمة أيِّ كتاب، فبإنَّ المؤلفين أوضحا الفكرة الأساسية مـن الكتاب، وسبب إعطائه هذا العنوان "أطلس الحضارة الإسلامية"، والمنهجية التي اتبعاهـا، ونوعية الكتابات التي تعرضت لموضوع هذا الكتاب، وما امتاز به في منهجيته وموضوعاته عن الكتابات الأخرى، وتوزيع موضوعات الكتاب على أبوابه وفصوله. يلاحظ أن الكتـاب في طبعته الإبحليزيـة جعل عنوان القسم الأول في مـنن الكتـاب بعنوان "السياق"، بينما كان عنوان القسم في قائمة المحتويات كلمة "origin" التي تعني "الأصل" أو "المنشأ" أو "الابتداء". وتبدو هذه الكلمة على علاقة لصيقة بعنوان الكتاب

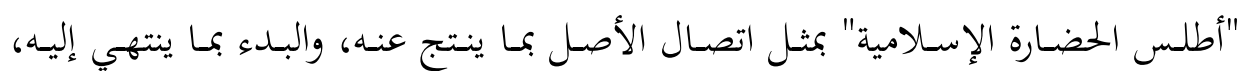

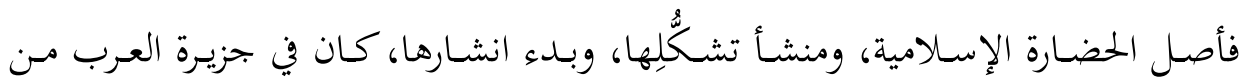
حيث المكان، وهذا هو عنوان الفصل الأول من القسم، وكانت اللغة والتاريخ (وهذا هو عنوان الفصل الثاني) الأصل الذي يعبر عن دور الشعوب والأقوام الذين سكنوا ذلك

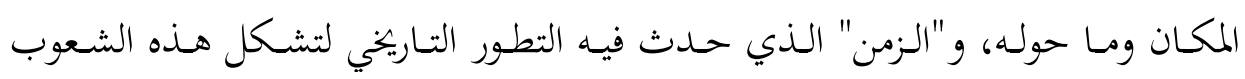
وتطور لغاهـا، فيكون العامل البشـري والعامل الزمني أصلين مناسبين لفهم الصورة التي كانت عليها الأمور يوم جاء الدين الجمديد. وبذلك تتهيأ الأذهان للحديث عن الدين والثقافة التي بناهـا هـذا الـدين فخرج مـن محـددات المكان والزمـان والأقوام، لـذلك كـان عنوان الفصل الثالث "الدين والثقافة". وبذلك يكون موضوع هذا القسم بفصوله الثلاثة أصلاً للحضارة الإسلامية، وإن كانت عناصر المكان والزمان والأقوام والدين والثقافة هي السياق العام الذي نشأت فيه الحضارة الإسلامية. 
أما القسم الرابع والأخير فجاء بعنوان "التجليات". ومن النظر في عناوين الفصول الخمسة عشر لهذا القسـم، فإنه يسهل تصنيفها في ثناث بحموعات في كل منها خمسة

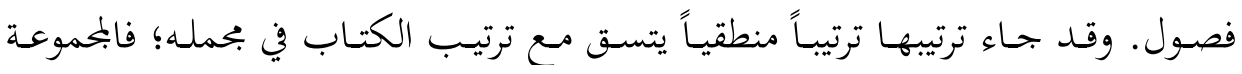

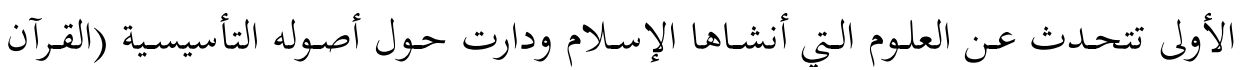

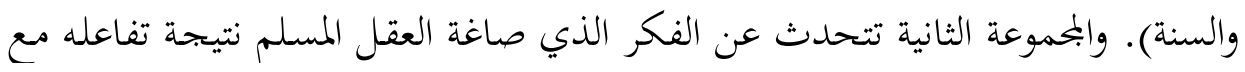
علوم الملّة وعلوم الملل والجماعات الثقافية والحضارية الأخرى إضافة إلى علوم الطبيعة. أمـا المجموعة الثالثة من فصول القسم الرابع فتولّت عرض صور التعبير عن الحضارة الإسلامية

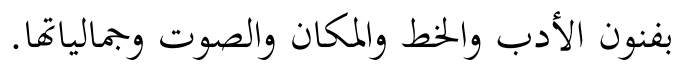

يمتاز الكتاب باحتوائه على أكثر من تسعين خحارطة، تدعم مادة الكتاب بمخططات

ورسوم وصور توضح توزع الأقوام والشعوب والأديان واللغات وحدود الدول والمنجزات

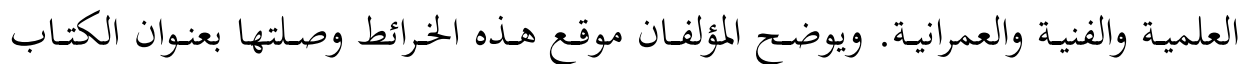

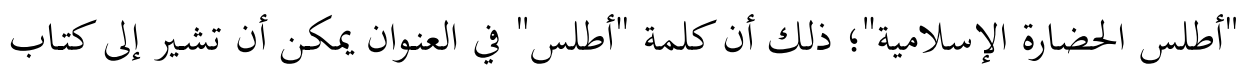

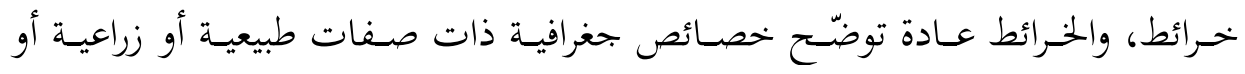
حضـرية أو سياسـية أو اقتصـادية أو عسـكرية... أمـا هـذا الكتـاب فيقـع ضـمن حقـل

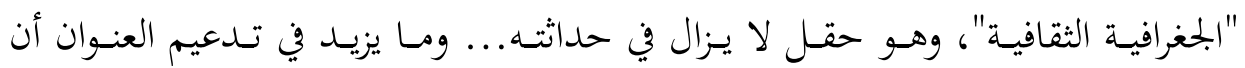
الكتاب ينطوي على بيانات وفيرة حول الثقافة والحضـارة في الإسلام، وقد جرى تمثيل

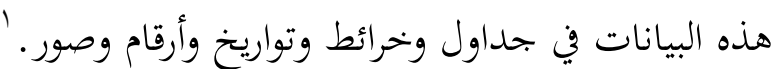
ولمزيــ مـن تنظيم هـذه البيانـات التي تتضمنها الخـرائط فقــ أضـاف المؤلفـان مسرداً

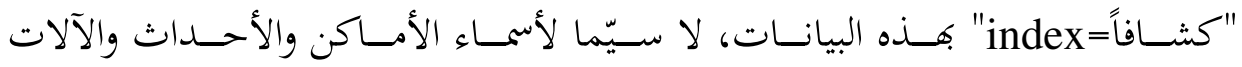

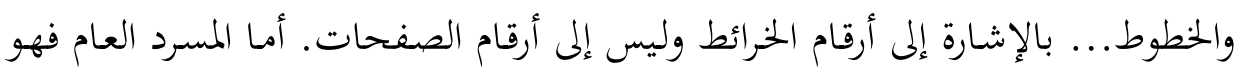

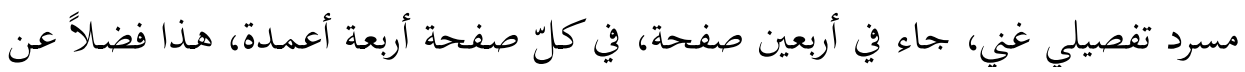
قائمة المحتويات التفصيلية التي احتوت على جميع العناوين الرئيسة والفرعية في الكتاب، وجاءت في أربع عشرة صفحة. 


\section{منهج التأليف في الكتاب}

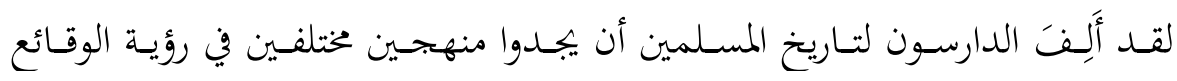

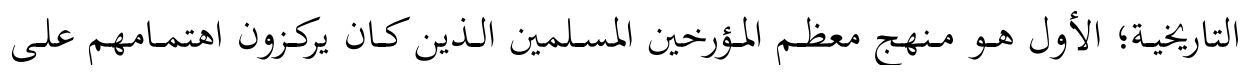

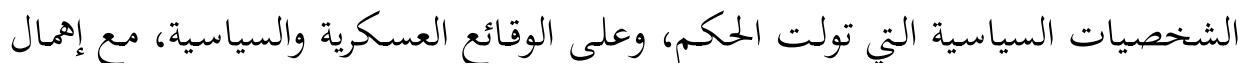

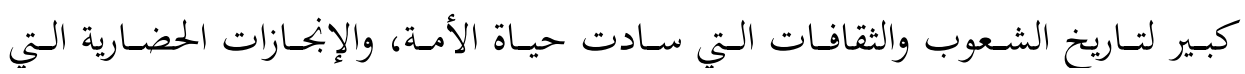

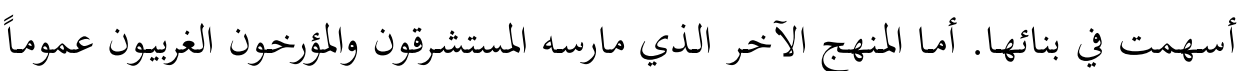

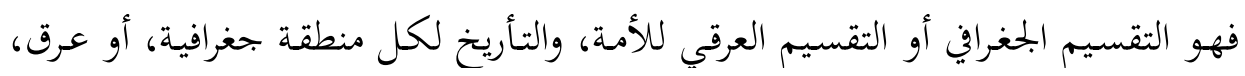

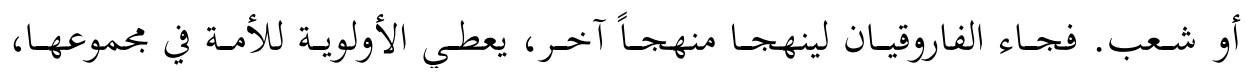

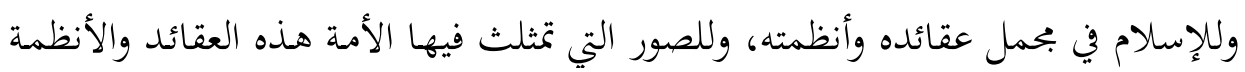

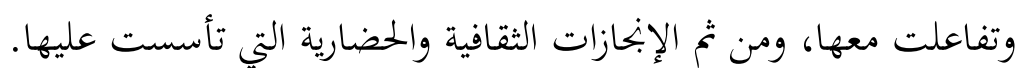

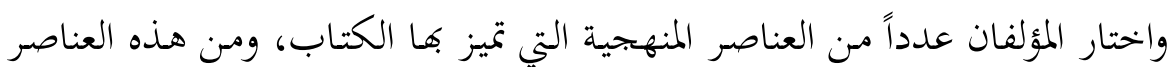

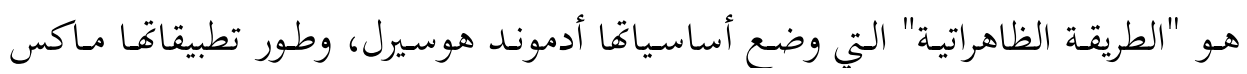

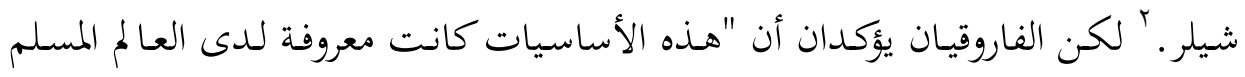

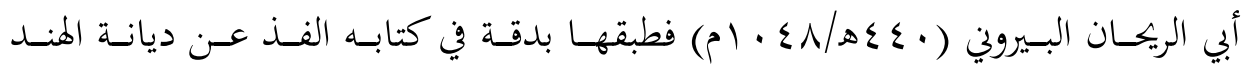

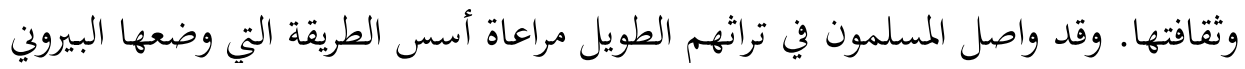

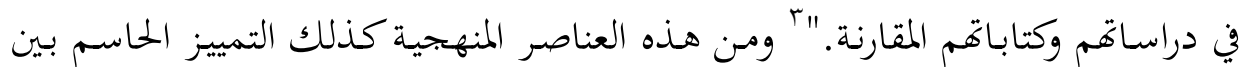

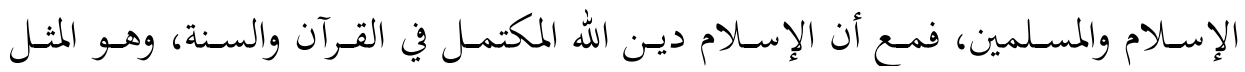

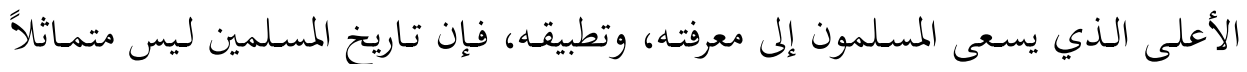

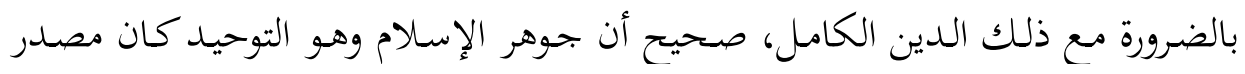

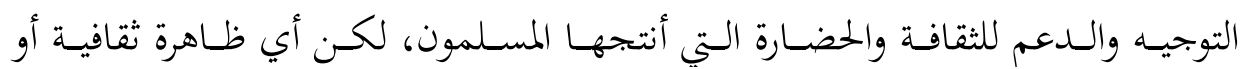

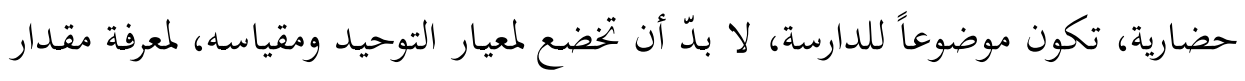

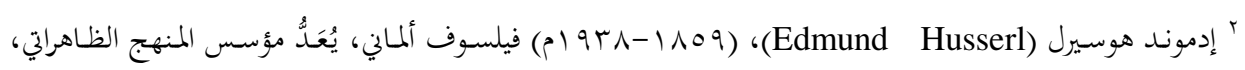

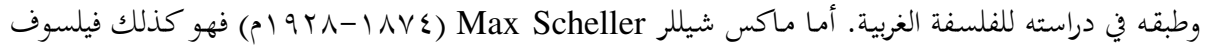
ألماني، اشتهر بتطويره لأفكار هوسيرل الخاصة بالمنهج الظاهراني وتطبيقه لهذا المنهج في دراساته للدين والأخلاق 


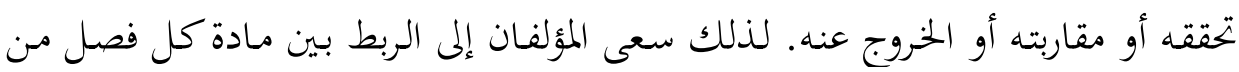

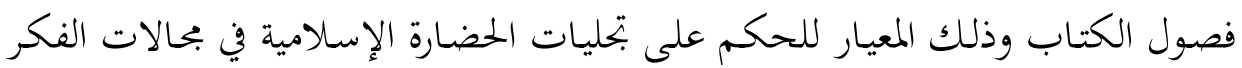
والفعل والتعبير.

وقد كانت الخبرة الغنية التي اكتسبها الفاروقيان مـ دراستهما المتعمقة، وزياراتما

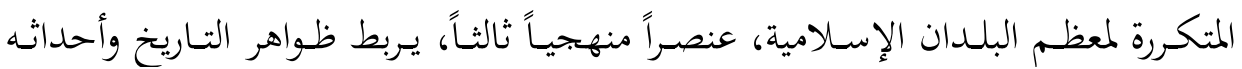

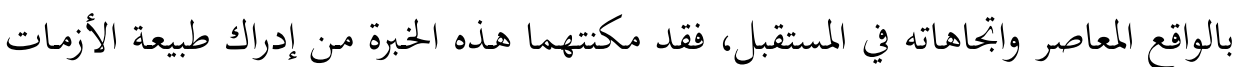

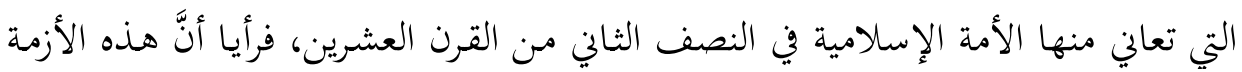

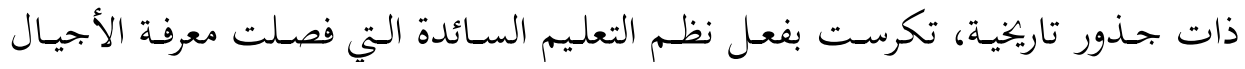

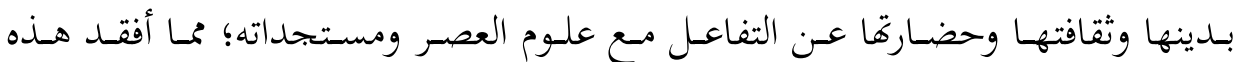

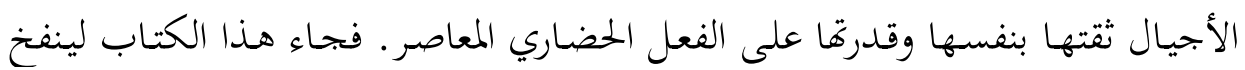

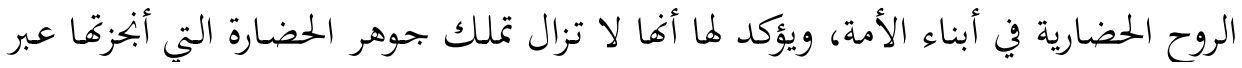
التاريخ، ويكشف عن قدرتا على استئناف البناء والإنحاز الحضاري.

وجاء الكتاب كذلك إسهاماً فريداً في مواجهة كتابات المستشرقين الذي أسرفوا في

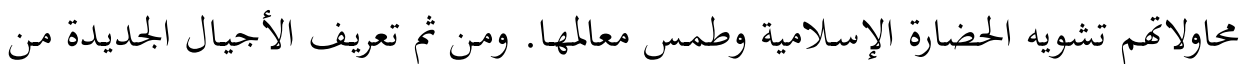
الغربيين بالإسـلام وإبنحازاته الحضـارية وقدراته الكامنـة على البقـاء والانتشـار والإنجـاز

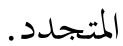

\section{السياق الذي نشأت فيه الحضارة الإسلامية}

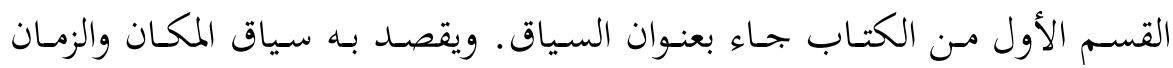
والإنسان. وتحدث فيه المؤلفان عن بلاد العرب التي كانت المهاد الأول لرسالة الإسلام.

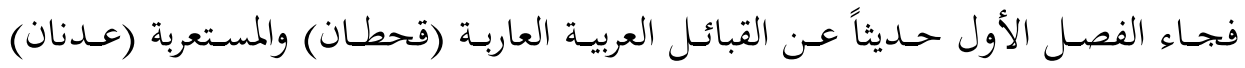

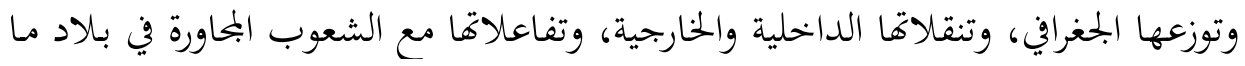

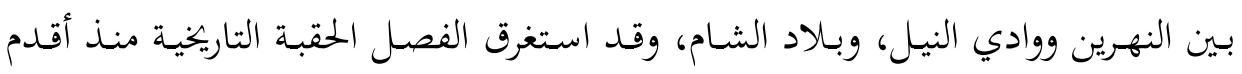

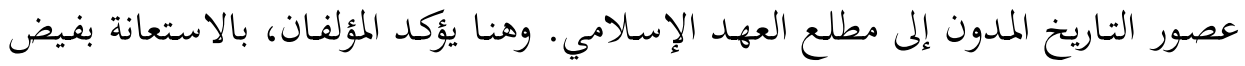




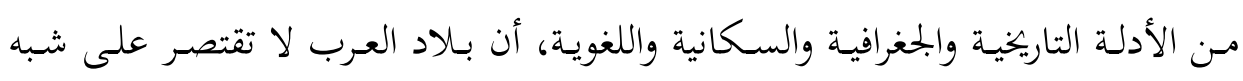

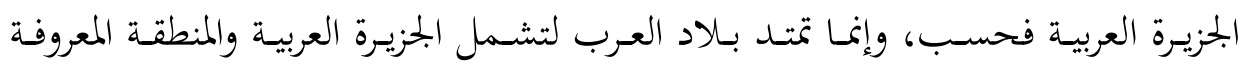
بالهالال الخصيب.

وتناول الفصل الثاني اللغة والتاريخ. ويعتمـ المؤلفـان على البحوث، والاكتشافات

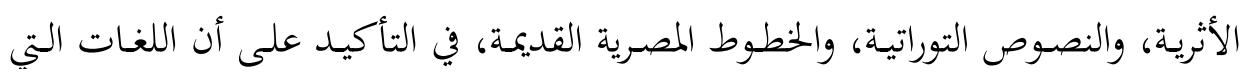

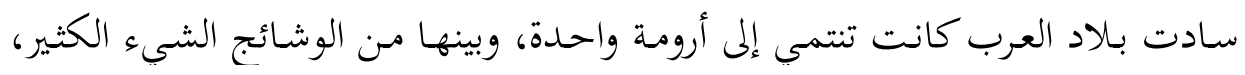

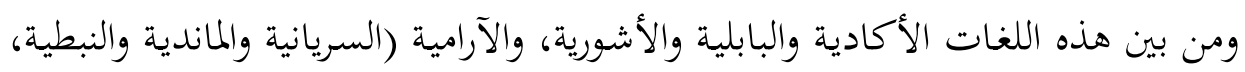

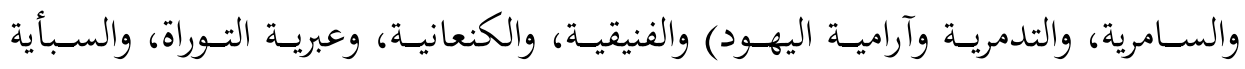

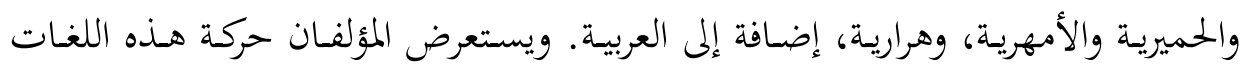

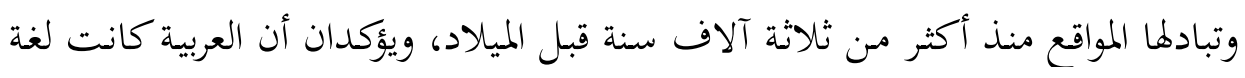

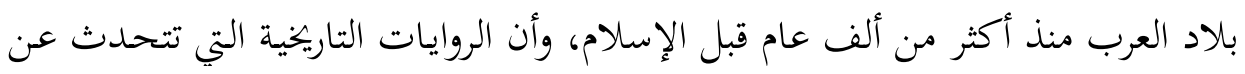

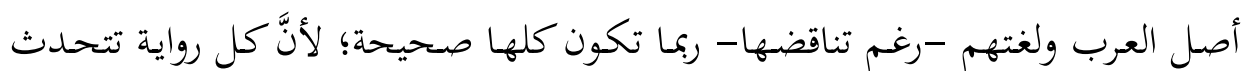

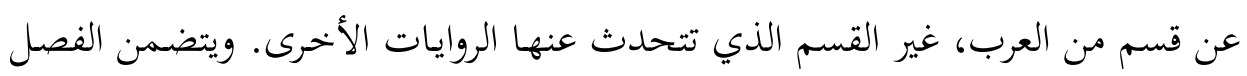

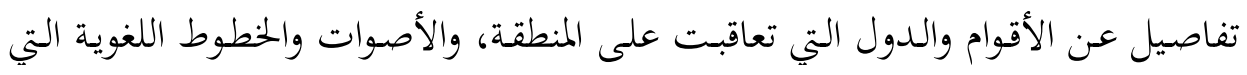

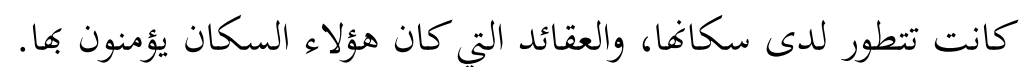

ويتحدث الفصل عن أسرة اللغات السـامية وخصائصها المشتركة، لا سيما ثلاثية الحروف والطبيعة الصوتية، والصرف، وتعدد المفردات الدالة على الشيء الواحد، وبنية

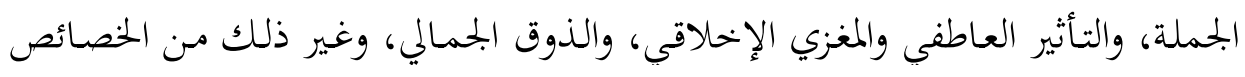

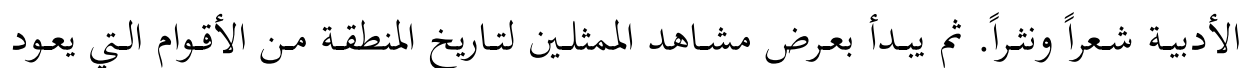

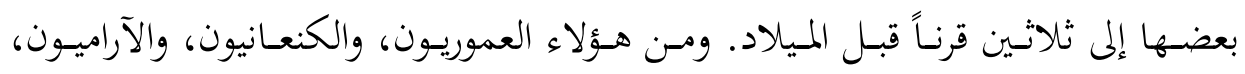
والآشوريون، والعبرانيون، والأكديون، وبدلاً من اقتصار الحديث عن كن كل من هؤلاء الأقوام على الجوانب السياسية والعسكرية، فإن الكتاب يركز على الثقافة والأدب والفن والفيول والقانون وأساليب الحياة، وصور التدين التي كانت تسود حياة الناس.

أما الفصل الثالث من هذا القسم فكان بعنوان الدين والحضارة. وجاء فيه استعراض

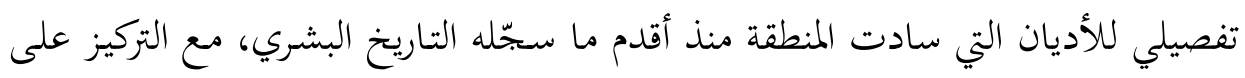


اليهودية، والمسيحية، والديانة المكية من عهد إسماعيل اليَلِّهِ حتى رسالة محمد عليه الصلاة

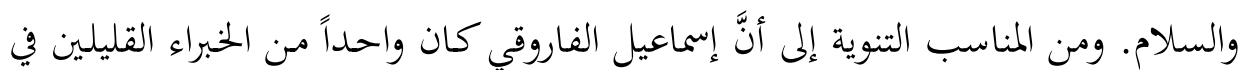

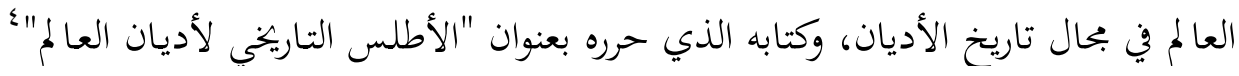
من المراجع المتميزة في موضوعه. وقد قام بوضع خطته واختيار المشاركين في الكتابة فيه،

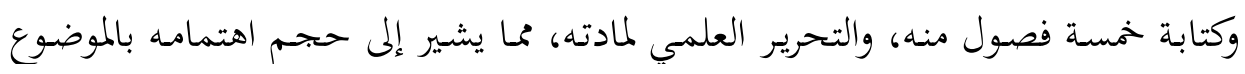
وخبرته فيه.

أمـا الطريق التي لجأ إليها المؤلفـان في هذا الفصل لعرض كل ديانة هي استخلاص

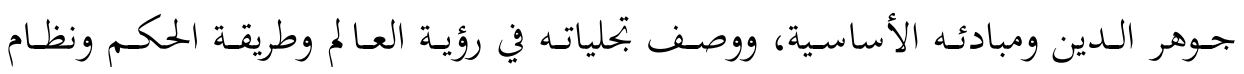

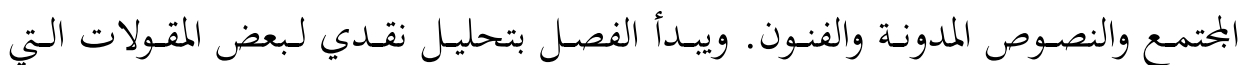

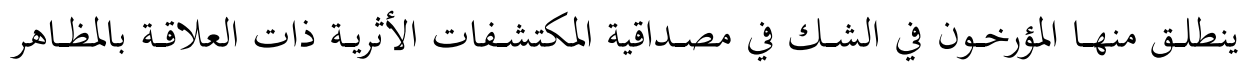

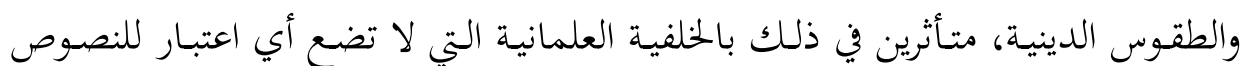

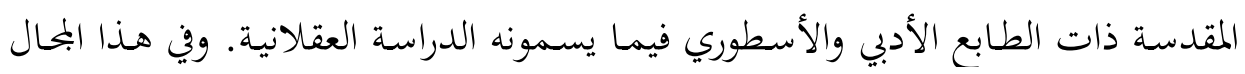

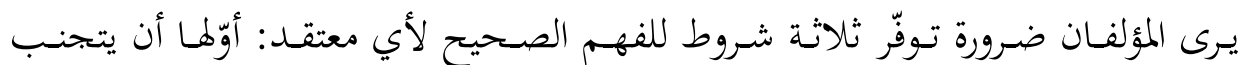

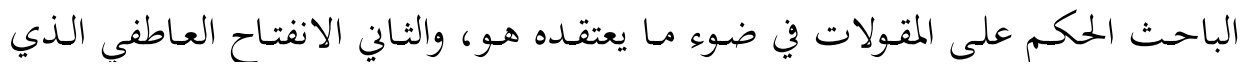

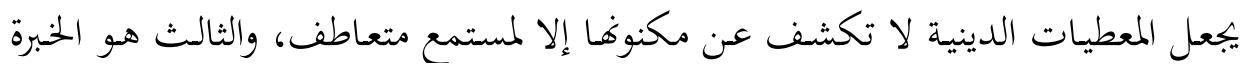

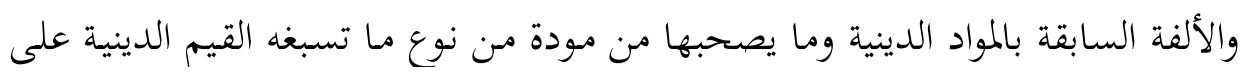

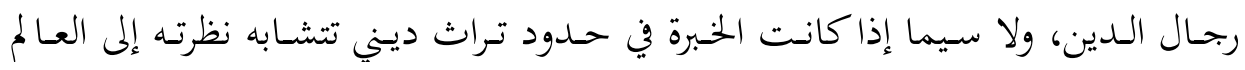

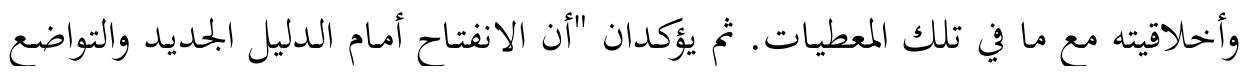

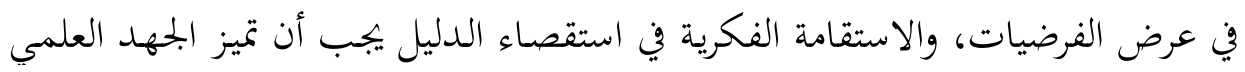

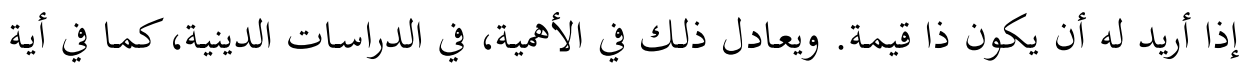

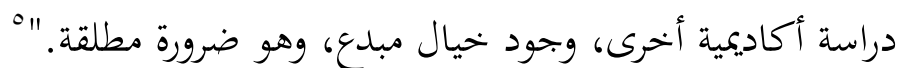

وممـا يلاحظظ على مـنهج المؤلفين في استعراض التـاريخ الـديني للمنطقـة الربط بـين

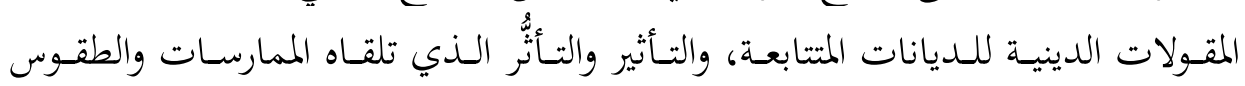

${ }^{4}$ Al- Faruqi, Ismail Ragi. Historical Atlas of the Religions of the World, New York and London: Macmillan Publishing Co., 1974. 
الدينيـة بالبيئة السياسية للشعوب والأقوام في المنـاطق البماورة. ولا يشسير المؤلفـان بصـورة واضحة إلى تراث النبوات كما وردت في القرآن الكريم في الاستعراض التاريخي للديانات

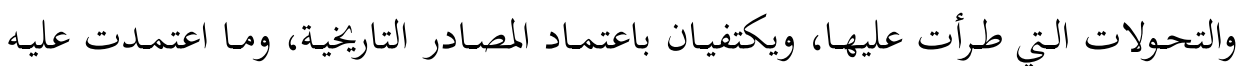

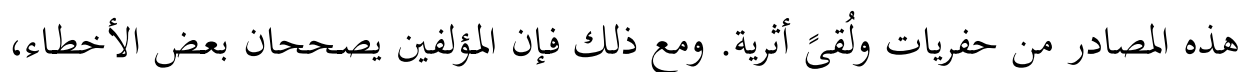

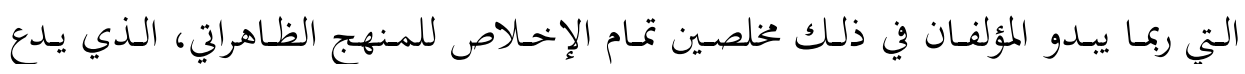
الأحداث تقول كلمتها كما سجلها التاريخ دون تدخل مـ الراوي، أو إصدار أحكام بناء على معتقداته. ومع ذلك فإن القارئ لا بد أن يجد ملامح الهوية العربية الإسلامية للدكتور إسماعيل الفاروقي وألفته بالآيات القرانية ذات الصلة بالنص التاريخي التي يورده.

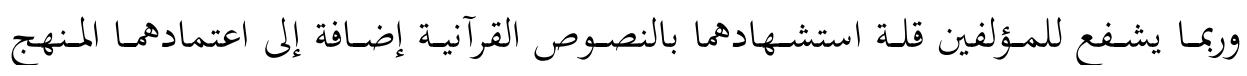

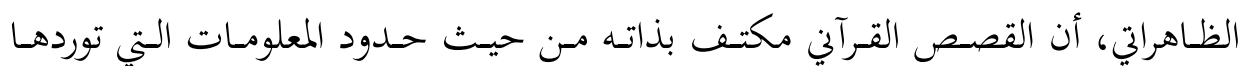
القصة، دون حاجة إلى استكمال عناصرها من مصادر أخرى غير القرآن الكريم والحديث النبوي الشريف، وأن هدف القصص القرآني هو التفكر والتدبر والاعتبار، وليس التدوين التاريخي للأحداث وفق تسلسلها واستكمال عناصرها.

\section{التوحيد جوهر الحضارة الإسلامية}

عنوان القسم الثاني من الكتاب هو جوهر الحضارة الإسلامية، ويبدأ المؤلف بتقرير

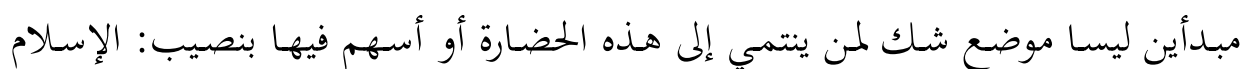
هو جوهر الحضارة الإسـلامية، والتوحيد هو جوهر الإسـلام. والتوحيد في الإسـلام رؤية

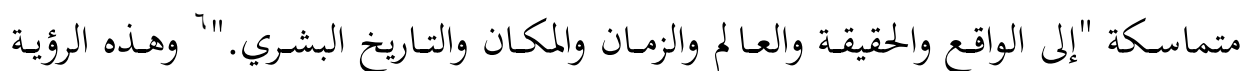

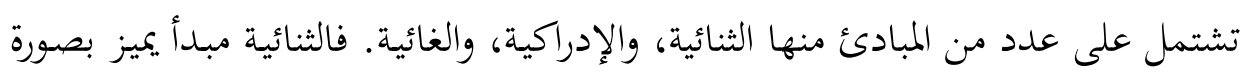
حاسمة بين الله الخالق والعالم المخلوق، فلا الخالق يتمثل في المخلوق أو يحل فيه أو يتوحد

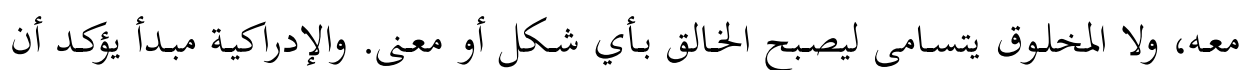

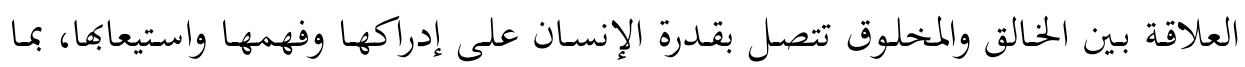

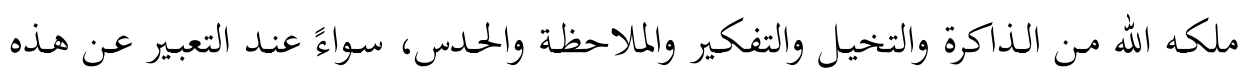


العلاقـة بوحي الله المنـزل إلى الإنسـان، أو بقـدرة الإنسـان على إدراك الإرادة الإلهيـة مـن خلال الملاحظة الحسية للمخلوقات والتفكر فيها. أما مبدأ الغائية فيؤكد أن الله سبحانه

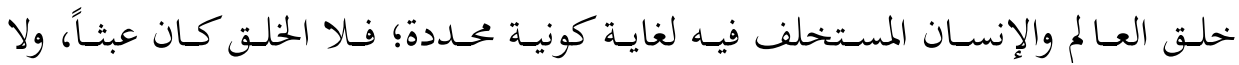
المخلوقات فوضى، فإرادة الله تتحقق في الأشياء والأحداث وفق قوانين وسنن، وإرادة الله تتحقق في الإنسان من خلال حرية الاختيار التي تستبع المسؤولية الأخلاقية عنها. وللتوحيد بوصفه جوهر الحضارة الإسلامية: جانبان جانب المنهج وجانب المحتوى، فجانب المنهج يشتمل على ثلاثة مبادئ منهجية هي: الوحدة والعقلانية والتسامح، أما جانـب المحتوى فيتعلـق بالمبـادئ نفسـها، فالتوحيـد أول مبـدأ في الفلسـفة الماورائيـة، وفي فلسفة الإخلاق، وفي علم القيم، وفي وحدة الأمة الإسلامية، وفي التجليات الجمالية. ويلاحظ أن الشرح والتفصيل في مبادئ التوحيد الخاصة بالمنهج أو المحتوى جاءت في هذا القسم من الكتاب بصورة موجزة جداً، ذلك أن تفصيلها كان في كتاب مستقل نشره المرحوم الفاروقي بعنوان: التوحيد وبحلياته في الفكر والحياة. ` واشتمل الكتاب على ثلاثة عشر فصلاً عرض فيها بحليات التوحيد في نظم الاعتقاد والمعرفة والقيم، واستوعب فيها المبادئ التي تشير إليها نصوص الإسلام ومقاصده، كما استوعب كذلك التجليات العملية في تاريخ الحضارة الإسلامية وإبحازات الشعوب الإسلامية. ويلاحظ القـارئ لهذا القسم مـن الكتاب أن المؤلفين يحيلان إلى عدد مـن البحوث التي نشـها كـل منهمـا في مواقع أخـرى حـول بتحليـات التوحيـد في الفكـر والحيـاة، كمـا يكثران مـن الإحالة إلى الآيات القرآنية الكريمة، والتنبيه إلى الفوارق الأساسية بين الرؤية التوحيديـة الإسـلامية مـن جهـة، ورؤى الفلسفات والأديـان الشـرقية والإغريقيـة والمصرية

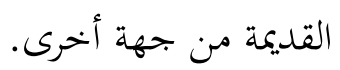

${ }^{7}$ Al-Faruqi, Ismail R. Tawhid: Implication for Thought and Life. Herndon: International Institute of Islamic Thought, 1402AH/1982AC.

ونكتفي في هذا المقام بهذه الإشارة، وللقارئ أن يقرأ المزيد في مراجعة متخصصة عن كتاب التوحيد يجدها في مكان آخر من هذا العدد من بملة إسلامية المعرفة. 


\section{الأفكار وتطبيقاتها ومؤسساتها}

القسم الثالث من الكتاب جاء بعنوان الشكل، وهو يأتي بعد تحليل جوهر الحضارة

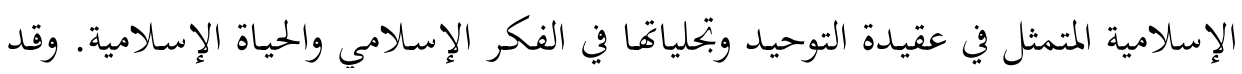

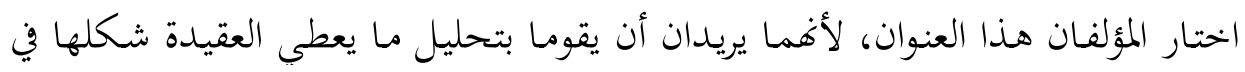

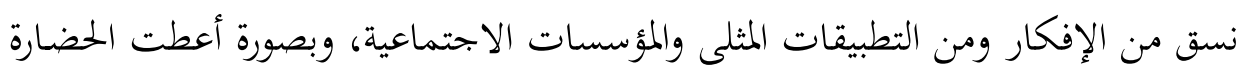
الإسلامية شكلها وشخصيتها، وأسهمت في ترسيخ تطورها وحضورها الفاعل في التاريخ. ويتكون هذا القسم من أربعة فصول هي:

القرآن الكريع: وفيه يستعرض المؤلفان حقائق الوحي وكيفياته وظاهرة النبوة وتاريخها، ولغة القرآن ونسيج الأفكار التي يتضمنها.

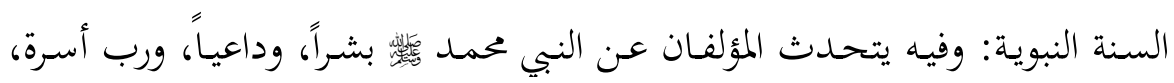
وزعيماً سياسياً.

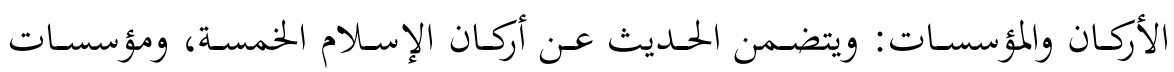

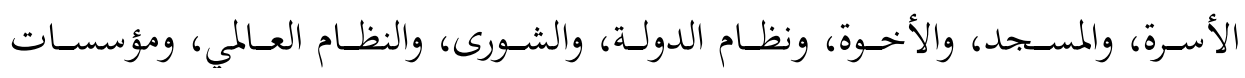

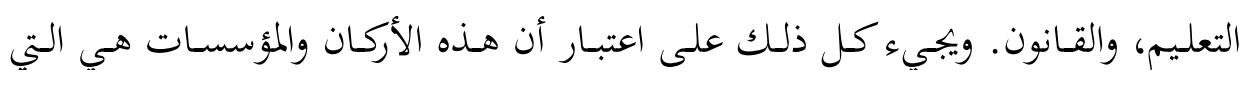
تعطي للحضارة الإسلامية شخصيتها ومظاهرها الشكلية التي تميزها.

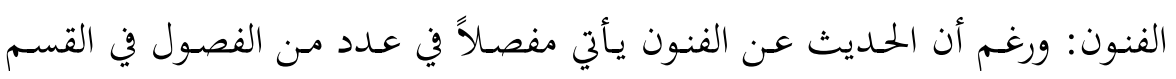

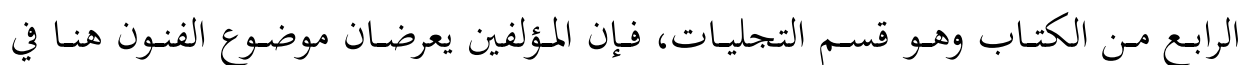

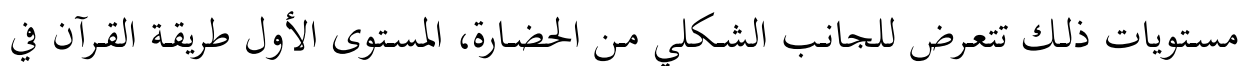

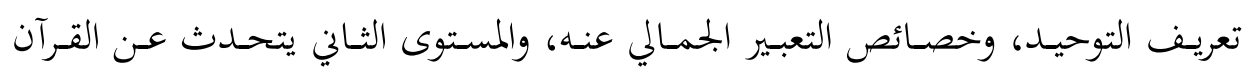

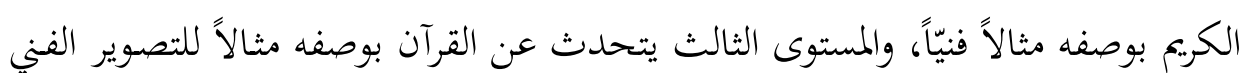
الدقيق.

إن الحديث عن القرآن الكريم هنا يبدأ بالحديث عن الصور الشكلية للوحي السابقة

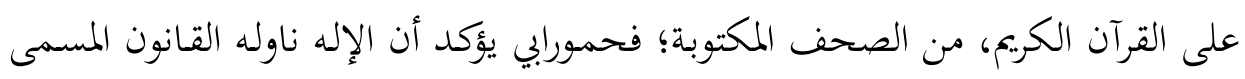


"شريعة حمورابي"، وأن الإله نفسه هو الحافظ لهذا القانون، والقانون نفسه يؤكد أنه نص

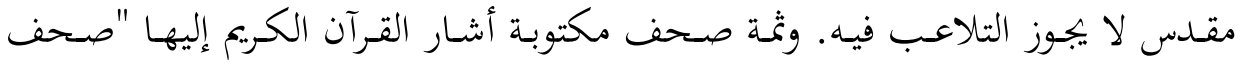

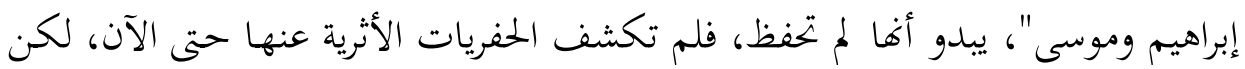

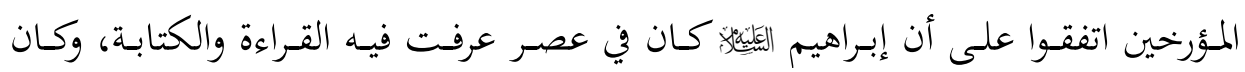

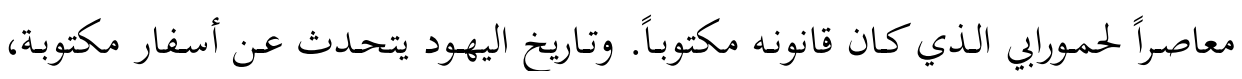

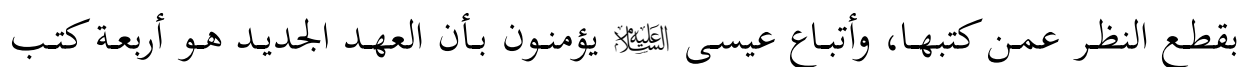
كتبها أربعة رجال معروفون في أزمان محددة.

تم يأتي الحديث عن القرآن الكريم حديثاً عن الشكل والبنية التي التي جاءت فيها السُّور والآيات، وعن الشكل الذي نزلت فيه وحفظت في الصدور وكتبت في السطور،

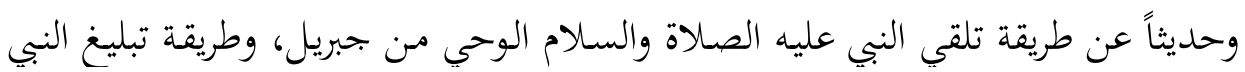

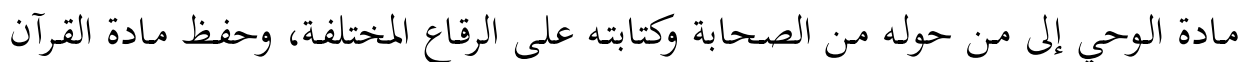

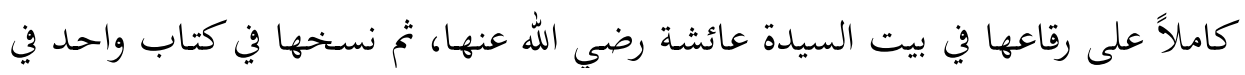

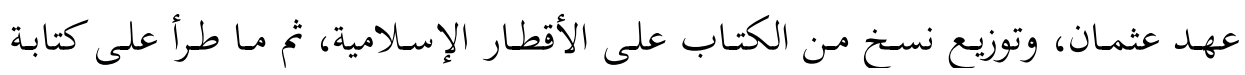

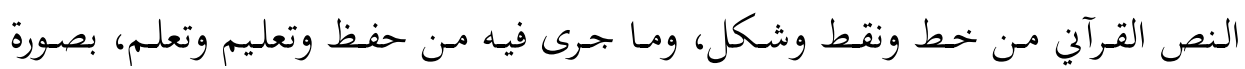

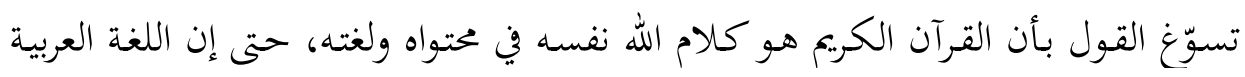
تجمدت في النص القرآن، فكل مكونات اللغة اتخذ قالبه في القرآن، ومن القرآن يستقي فئي

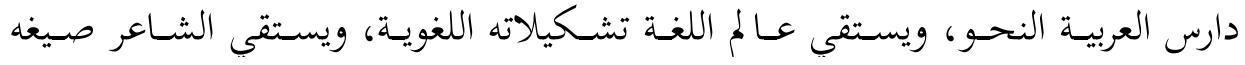

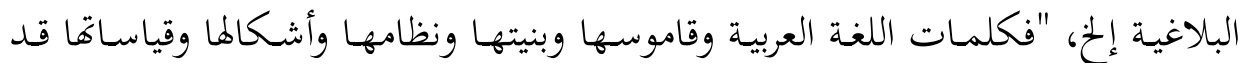

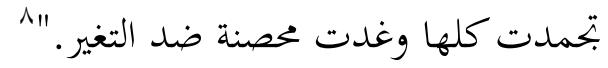

أما المحتوى الفكري في القرآن الكريم، ففي المركز منه محتوى العقيدة، التي تؤمن بالله

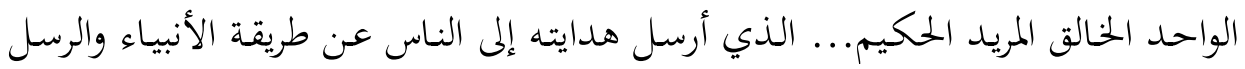

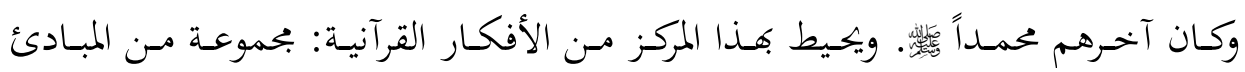

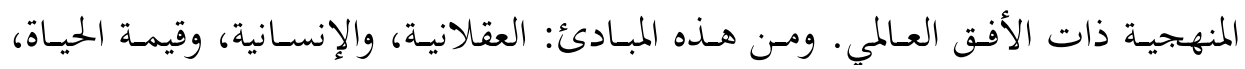
والانتماء إلى البحتمع البشري. 
أما السنة النبوية فإن المؤلفين يستهالان الحديث عنها بالتأكيد على أفها ترجمة لحقائق

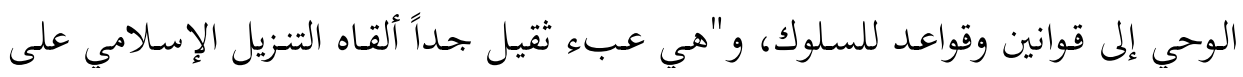

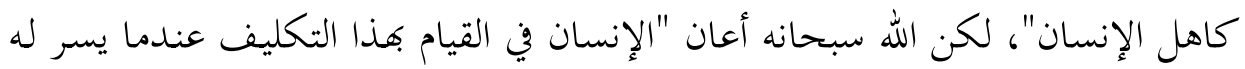

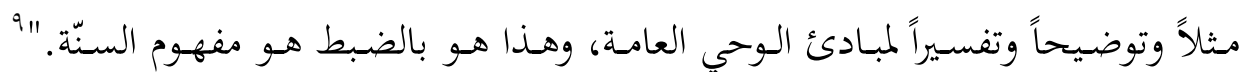

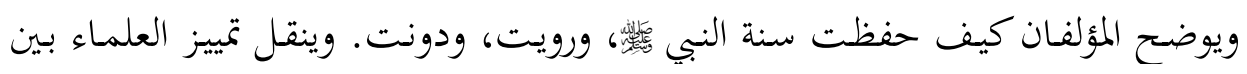

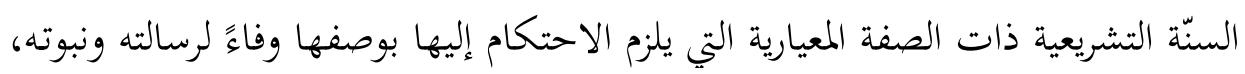

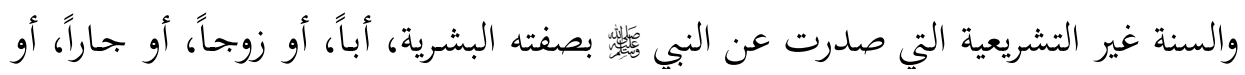

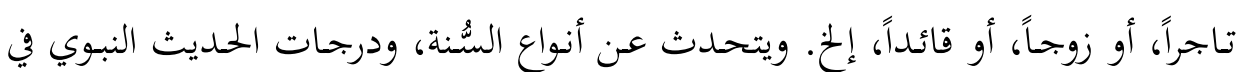
الصحة والضعف.

لكن جـوهر الإسـام لم يقتصـر على الشـكل الذي ورد في القرآن الكريم في صسور

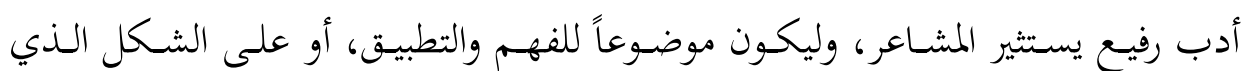

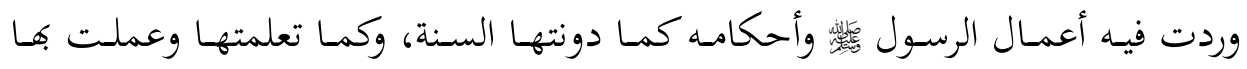
أجيال المسلمين بعد ذلك، وإنما بجلّى هذا الجهوهر في الأركان والمؤسسات الاجتماعية التي فرضـها الـدين وأقامتهـا الجماعـة، بصسورة تيسّر فهـم الرسـالة الخاتمـة للـدين، وأن أركاهــا ومؤسسـاها هي وحسي يـوحي، وأهـا شملـت أغلـب أنشطة الحيـاة الشخصسية والأسـرية والاجتماعية والعالمية، وأن الشريعة تقتضي حماية هذه الأركان والمؤسسات وتنظيم عملها،

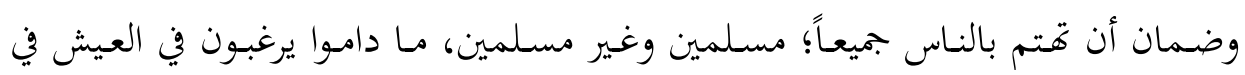
ظل هذه الشريعة.

ويسورد المؤلفـان ضـمن سـياق الحسديث عـن الشـكل في الحضــارة الإسـلامية أركـان الإسلام الخمسة، بصفتها أنظمة مفروضة بصور مقننة وشكليات محددة ومواقيت مقدرة، تعود المسـلم على إيقـاع سـلم في الحيـاة، على مستوى اليوم والأسبوع والشـهر والسَّـنة

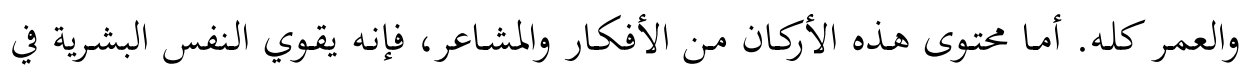
عزمها على إرادة الخير وفعله، وملى العالم بالقيم النبيلة. ولا يقتصر حديث المؤلفين عن ولن 
الأركان الخمسة في الإسلام بوصفها عبادات وشعائر، وإنما يتجاوز لذلك للحديث عنها بوصفها أنظمة ومؤسسات.

أما المؤسسات التي قنن لها الإسلام وعرفتها الحضارة الإسلامية بصورة متميزة، فقد

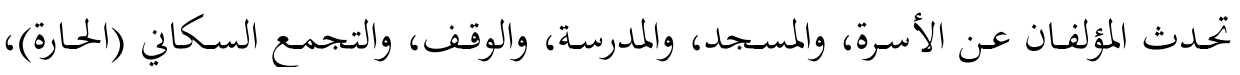
والحسبة، والخلافة. وقد ميز المؤلفان بين المبادئ العامة والقيم العليا التي يجب أن تلتزم بها هذه المؤسسات من جهة، والتنظيم الهيكلي والأشكال الإدارية والوسائل العملية لتحقيق هذه المبـادئ والقيم، وهي تختلف وتتعدد صورها، ويترك للجماعـة المسلمة أن تطور في

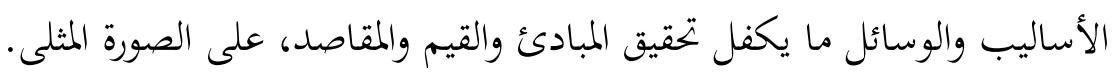
وقد جاء الفصل الأخير من هذا القسم الثالث من الكتاب بعنوان الفنون. ويوضح المؤلفـان هنـا "أن الثقافة الإسـلامية هي ثقافـة قرآنيـة"؛ لأن "القـرآن الكـيم يقـدم المبـادئ

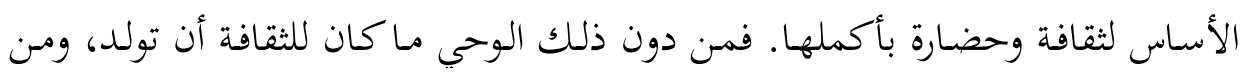

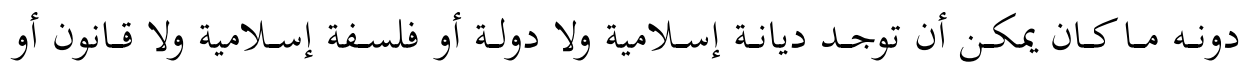
بحتمع إسلامي، ولا نظام سياسي أو اقتصادي إسلامي. ومثلما يصح بالتأكيد رؤية هذه

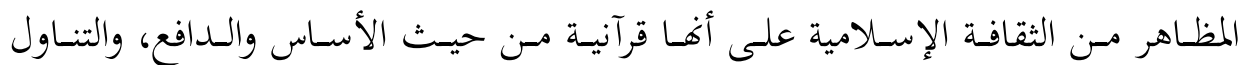

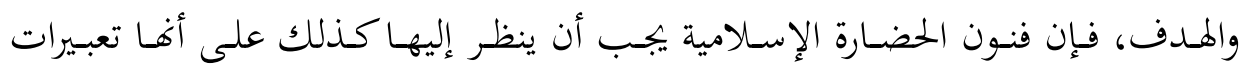

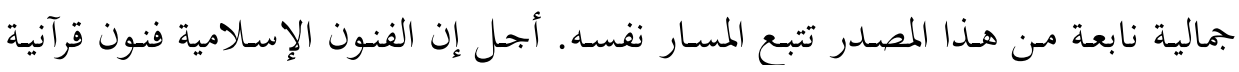
حقاً. " . 1.

ويفسر المؤلفان بعد ذلك بقدر من التفصيل كيف يمكن النظر إلى الفنون الإسلامية

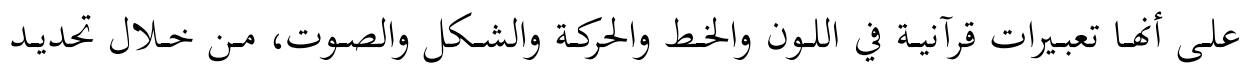
ثلاثة مستويات يقوم عليها هذا التفسير:

المستوى الأول: القرآن يعرّف التوحيد ويحدد خصائص التعبير الجمالي عنه من خلال

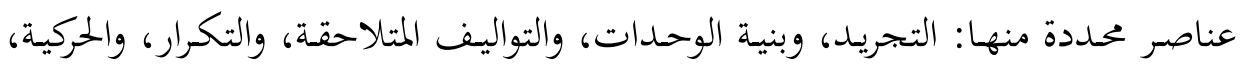
والتداخل. 
المستوى الثاني: القـرآن هـو مثـال فني؛ فهو وإن كان تنـزيلاً إلهياً بشكله ومختواه

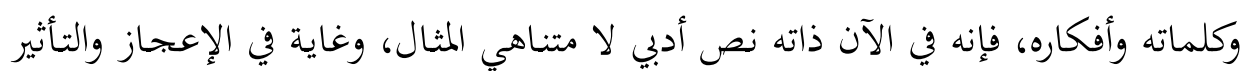
الجمالي في ألفاظه ووحداته وأقسامه وموسيقاه وإيقاعاته.

المستوى الثالث: القرآن هو مثال للتصوير الفني الدقيق؛ لأنه زوّد الحضارة الإسلامية

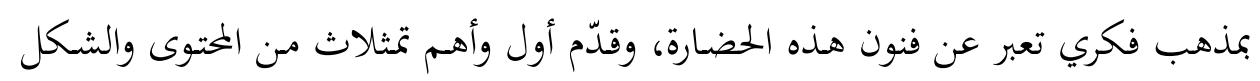

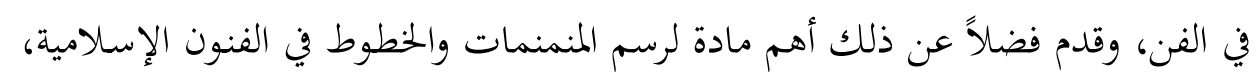
فكانت الآيات القرآنية مادة للخطوط في تزيين المنسوجات والماتلابس والأواني والصناديق الماديق

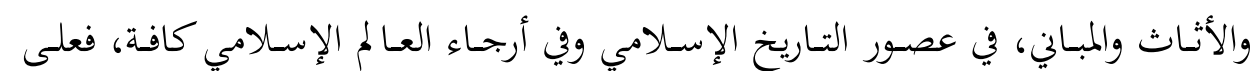

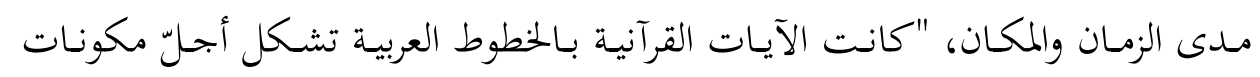

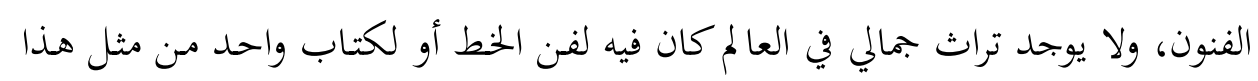

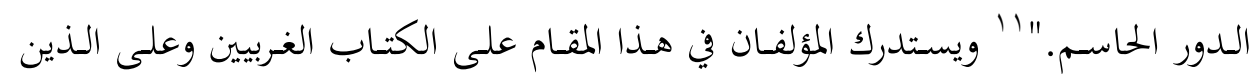

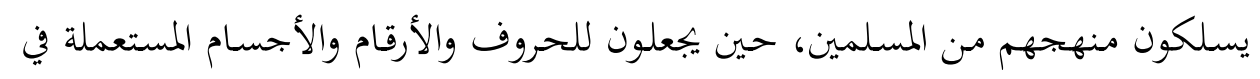

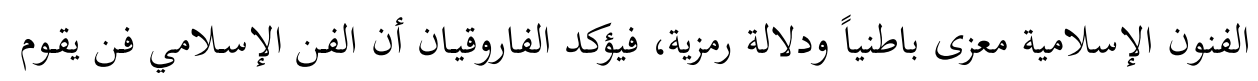

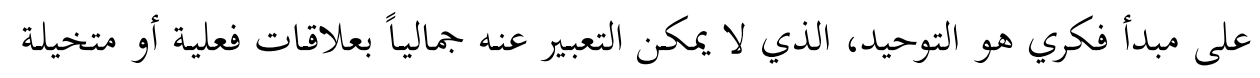
بين الطبيعة والله سبحانه، فكل شعائر الإسلام شعائر وظيفية لا رمزية.

وأخيراً يشير المؤلفان إلى الثغرة القائمة في ميدان الجماليات الإسلامية وتاريخ الفن في

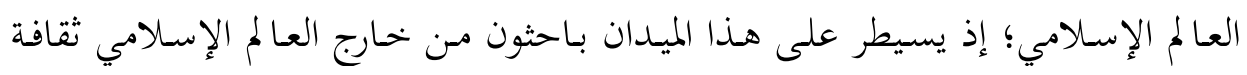

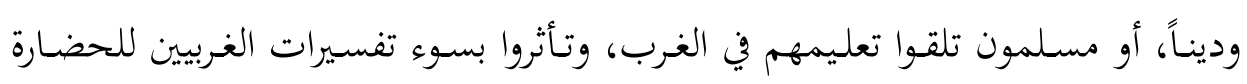

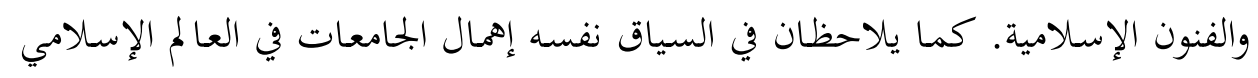

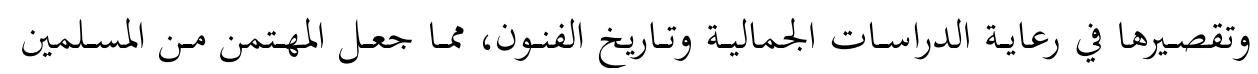
يضطرون إلى الدارسة في الجامعات الغربية ويقعون فريسه لتوجهاتها وتفسيراتما. 


\section{تجليات الحضارة الإسلامية في الفِعْل والفِكُر والتَّبير}

هذا هو موضوع القسم الرابع من الكتاب، وهو أكبر الأقسام ويتكون مـ خمسة

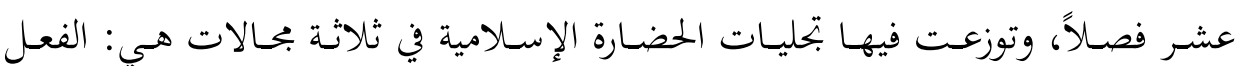
والفكر والتعبير. ويقصد بمجال الفعل أحداث نزول الرسالة ومقاومة الملأ للدعوة وما لقيه ولتهيه

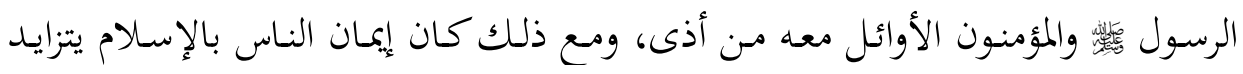

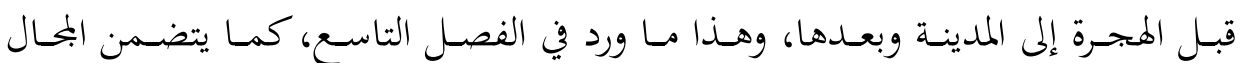
الحديث عن تشكل الدولة الإسلامية وحركة الفتوحات الإسلامية في بلاد العرب ثم فيما حولها شرقاً وغرباً، ودخول كثير من الشعوب دون أشون أن تصلها حركة الفتوحات، لا سيما

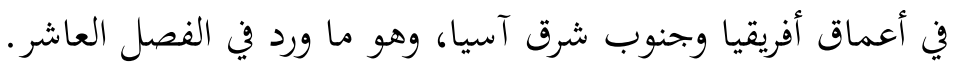

أمـا بحـال الفكـر فتــ عرضـت موضـوعاته في الفصـول الثمانيـة التاليـة. وتضـمنت

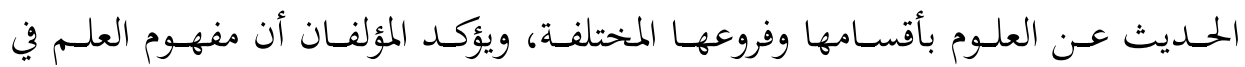
الإسلام مفهوم متميز عنه عند الطوائف والفلسفات الأخرى، فهو إدراك عقلائ تحريبي حدسي لكل ميدان مـن ميادين الواقع، ومعرفة نقدية للإنسـان والتـاريخ والعالم المادي، ويخضع للاختبار والتطبيق ويؤدي إلى نتائج عقود إلى الفضيلة، فالمسلم لا يتلقى المعرفة عن مصدر بجهول يتصف بالسّرية، أو عن طريق كشف إشراقي ذاتي تأملي، ولا يبحث

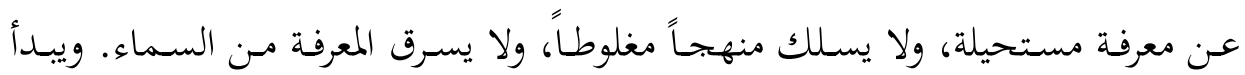

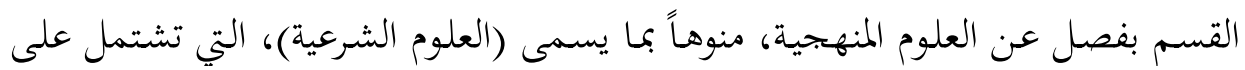
علوم القرآن والحديث واللغة والفقه. ويتخصص هذا الفصل بالحديث التفصيلي عن علوم اللغــة التي تشـتمل على الأدب والنحـو والصـرف، وعلـم المعـاجم، وأهميـة هـــه العلـوم المنهجية بوصفها مفاتيح لعلوم الشريعة الأخرى.

يلي ذلك فصلٌ كاملٌ لكلِ من علوم القرآن، وعلوم الحلديث، وعلم الفقه ويسميه

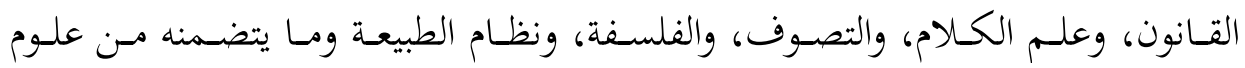

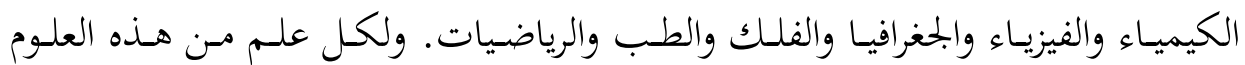


نشأته وتطوره، وأصوله وفروعه، وطرقه ومناهجه، وأعلامه ومدوناته. وقد جال المؤلفان في تفاصيل المسائل في كل علم منها.

ويخصص المؤلفـان الفصول الخمسـة الأخيرة للطرق المختلفـة مـن التعبير في الحضـارة

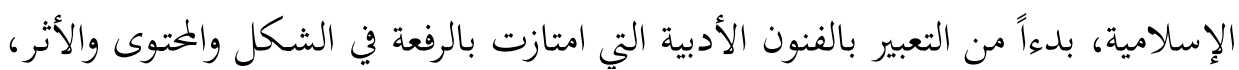

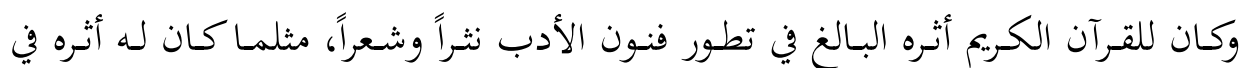

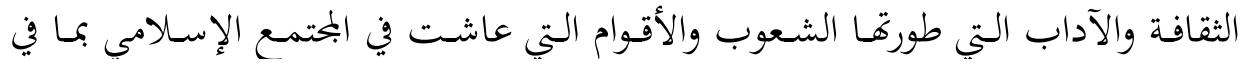
ذلك غير المسلمين من اليهود والنصارى. وامتد ذلك الأثر ليتجاوز اللغة العربية إلى لغات

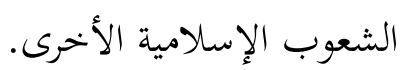

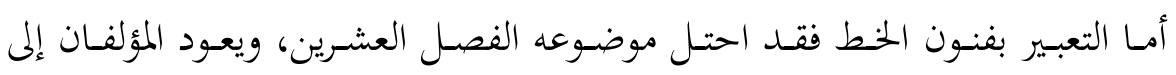

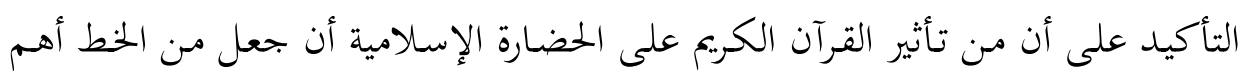
شكل فني فيها على امتداد الزمان والمكان. وفي هذا السياق يتحدث المؤلفان عن تطور الكتابة العربية، وتطور طرق استنساخ القرآن الكريم، وظهور أنواع الخطوط العربية: الكوفي والنستي والديواني والتعليق والتفرعات المتعددة لكل منها. تم استخدام هذه الخطوط في فنون الزخرفة للمباني والأدوات والنسيج وغيرها. وتخصص الفصـل الحـادي والعشـرون مـن الكتـاب بالحسديث عـن الزخرفـة في الفنون الإسلامية، مع التأكيد على الوظائف الفريدة للزخرفة في هذه الفنون. ذلك أن الزخرفة في

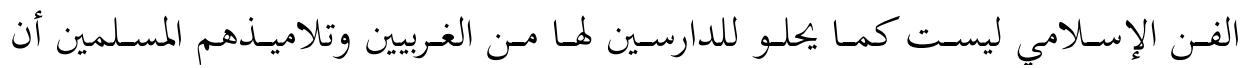
يفسروها، بأها شيء يضاف بشكل سطحي إلى العمل الفني بعد اكتماله؛ لتجميله أو الو وسيلة إشباع شهوات شعب يبحث عن اللذة، أو أها وسيلة لملء فضاء وبتحنب الفراغ، فعلى العكس من ذلك بحد التصاميم الزخرفية في كل منطقة من مناطق العالم الإسلامي، وي كل عصر من عصور التاريخ الإسلامي تؤدي أربع وظائف هي: - التذكير بالتوحيــ؛ مـن خـلال تقـديمها أنسـاقاً لا متناهيـة ترفع الشـي مـن بحـال الانتفاع الصرف، وبتعل منه تعبيراً عن النظام الفكري في الإسلام. 
- ـ تغيـير مظهر المواد؛ بـالطلاء أو التلبيس، وبإخفـاء الصففات الكامنـة في المـواد،

وعدم الاكتراث بغنى المادة؛ لأن العمل الفني الإسـلامي يستمد خصوصيته وامتيازه مـن أثر تلك المواد لا من قيمتها الداخلية.

- تغيـير مظهـر البني لتحويـل الاهتمـام بعيـاً عـن العناصـر والخصـائص المبتذلـة، وتوجيهة إلى منزلة أسمى من التعبير والمعنى.

- التجميـل، وهي وظيفـة تشـترك فيهـا الزخرفـة الإسـلامية مـع التقاليـد الفنيـة في

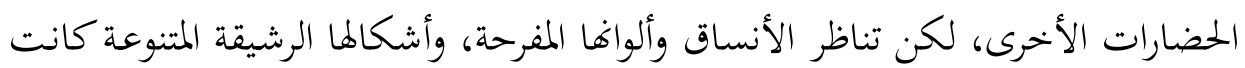
دائماً موضع إعجاب الناظرين إليها. ثم يتوسع الفصل كثيراً في الحديث عن التنوع في الفنون الزخرفية الإسلامية، وأساليبها

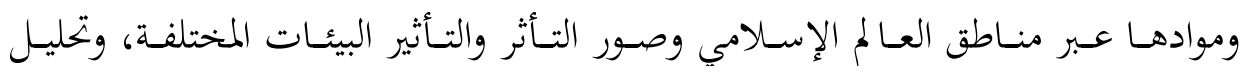
الوحدات الأساسية في الأشكال الزخرفية الهندسية والنباتية والحيوانية والمعمارية وغيرها. ويـأتي بعـد فصـل الزخرفـة فصـل آخـر عمّــا يسـميه المؤلفـان فنـون المكـان. ويـرفض

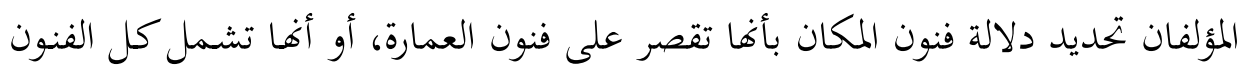

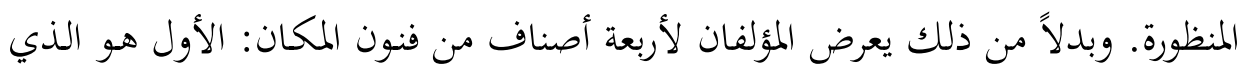

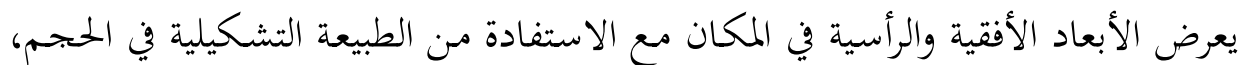

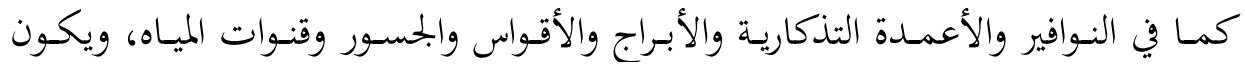

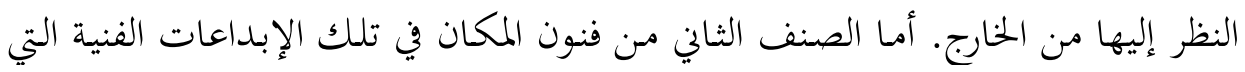

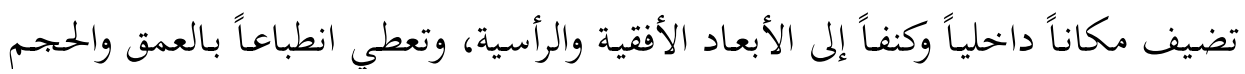

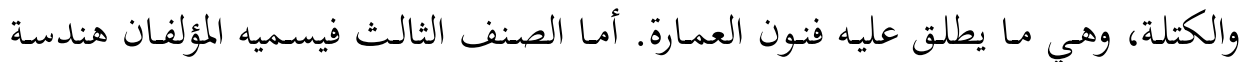
المناظر الطبيعية الذي يشتمل على الإبـداعات الجمالية في أعمال البستنة وهندسة الرّي

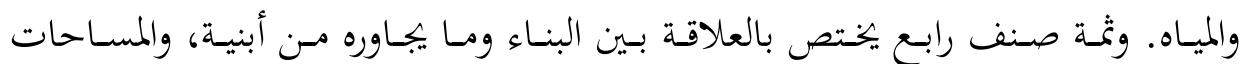

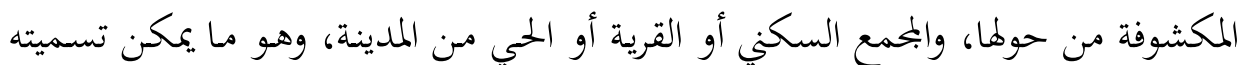
بفنون تخطيط المدينة والريف. ويتوسع المؤلفان في تفاصيل وخصائص هذه الأصناف من ون فنون المكان، والتمثيل عليها وتحليل تكويناتحا الفنية. 
وآخر فصول الكتاب هو فصل عن التعبير بالصوت أو هندسة الصوت في الفنون

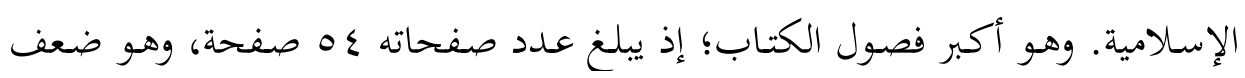
متوسط عدد صفحات فصول الكتاب. ويتضح من المراجع التي يهيل إليها الفصل كثرة

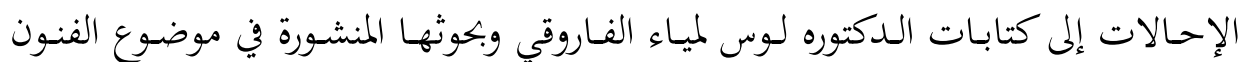
الصوتية الإسلامية، وهو موضوع اختصاصها العلمي، وخبرتها البحثية والتدريسية. لكن

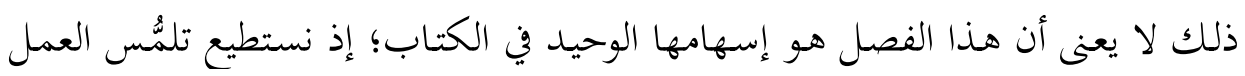

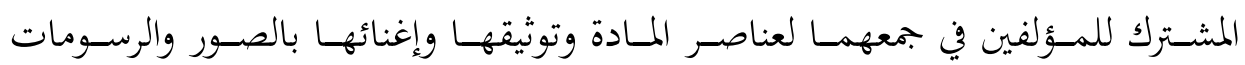
والمخططات التوضيحية، ويلاحظ أن كثيراً من الصور قد التقطتها الدكتوره لوس الفاروقي

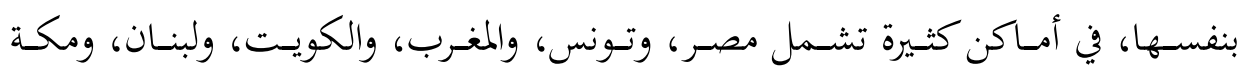

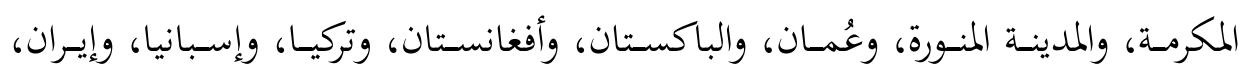

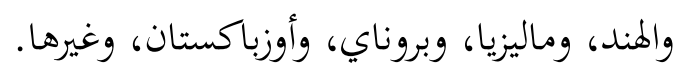

وكما هو الحال في الفصول السابقة من الكتاب، تعرّض هذا الفصل لقضية الأحكام الشرعية التي تضبط هندسة الصوت، وأجناس الفنون الصوتية، وسياقات الأداء الصوتي،

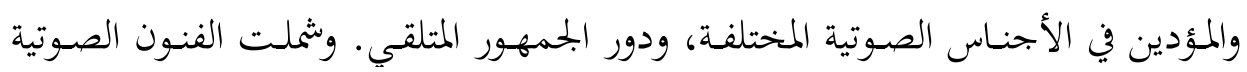

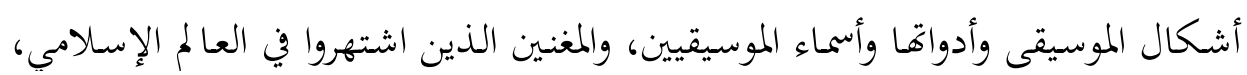

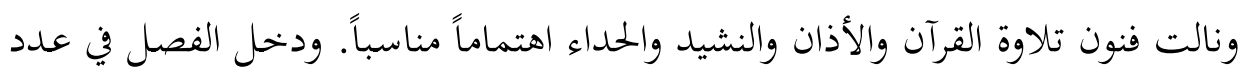

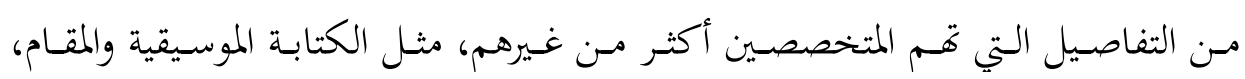
والخصائص الأساسية لفنون الصوت.

وقـد يكون هـذا الفصل على وجـه التحديـد فريـاً في موضـوعه، وطريقـة عرضسه، لا

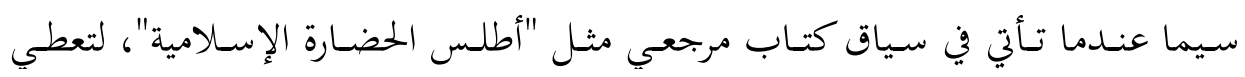

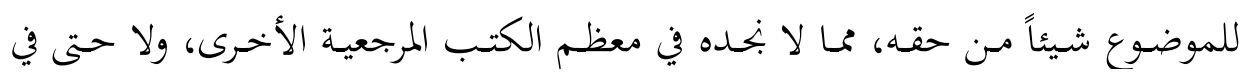
الكتب المتخصصة.

وقد لخص الفصل إحدى النتائج الأساسية بخصوص هندسة الصوت بالتأكيد على أن "الفنون الصوتية في الثقافة الإسلامية لم تكن محض بتميع لأساليب إقليمية مستعارة 
مس شعوب شتى وضعت بجسوار بعضها لتؤلف موسيقى الشعوب الإسـلامية." بـل إهـا

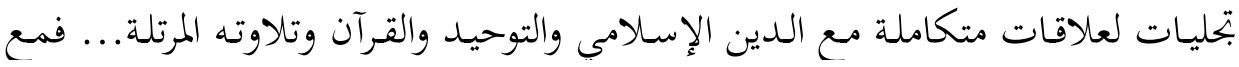

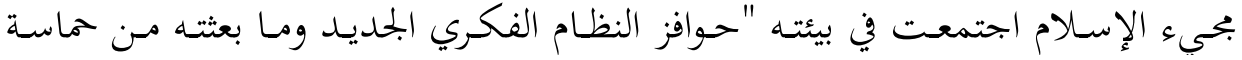

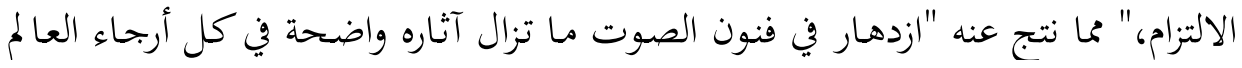

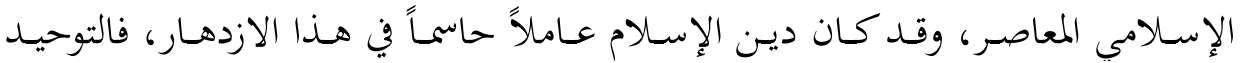
وصوره في القـرآن الكريم لم يقتصر على التـأثير في العديد مـن الجوانـب الاجتماعيـة مـن

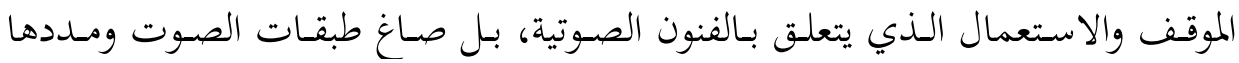

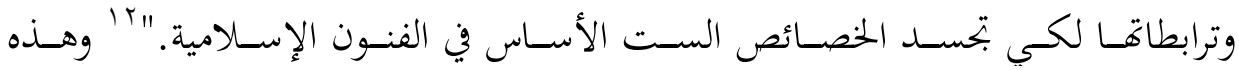
الخصائص هي: التجريد، وبنية المقام، والترابطات المتتابعة، والتكرار، والحركية والتعقيـد. وهي الخصائص نفسها التي وجدناها في سائر بحليات الحضارة الإسلامية.

خاتمة:

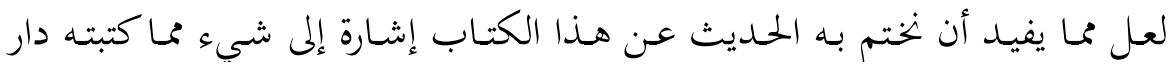

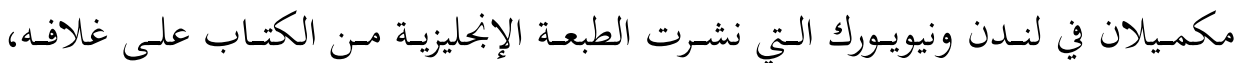

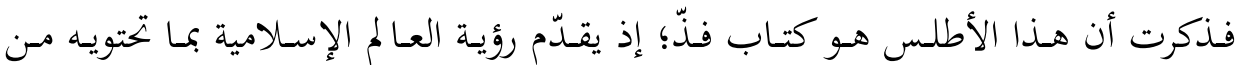

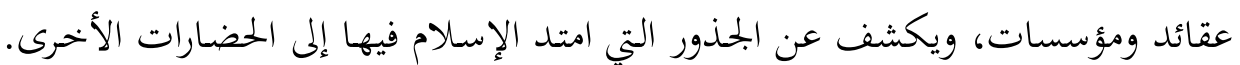

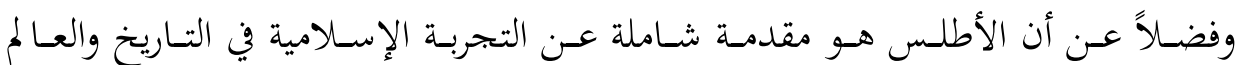

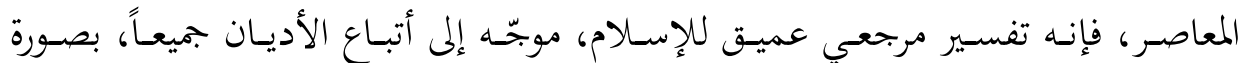
يصدق عليها القول: الإسلام يتحدث عن نفسه. ولا يقتصر الكتاب على عملى كونه تأريخاً

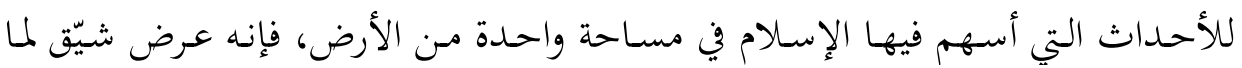

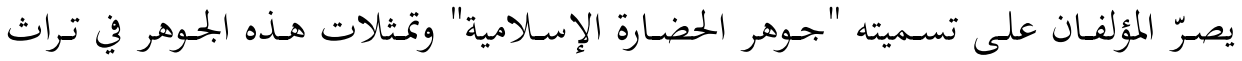
المسـلمين في الفنـون والعلوم والقـانون السياسـة والفلسفة. إن قيمـة الكتـاب تتمثل فيمـا

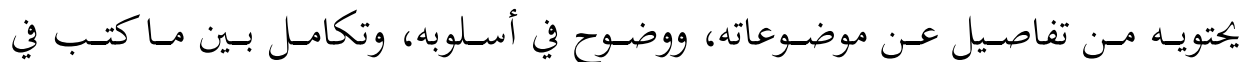

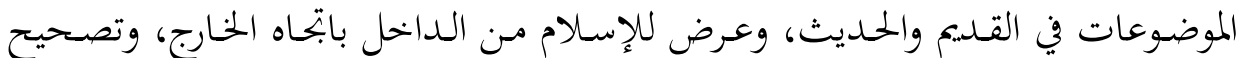
لصورة الإسلام وحضارته التي بالغ الغربيون في تشويهها. 